\title{
DIRETORES/AS, PEDAGOGOS/AS E PROFESSORAS: INFORMANTES-CHAVE DOS INTERDITOS SOBRE A DIVERSIDADE SEXUAL E HOMOFOBIA NA ESCOLA
}

\author{
Isaias Batista de OLIVEIRA JÚNIOR ${ }^{1}$
}

\begin{abstract}
RESUMO
O presente artigo apresenta resultados parciais de uma investigação em torno da diversidade sexual e da homofobia centrada na escola. A investigação decorreu em treze escolas públicas de Ensino Médio em distintos municípios do Norte do Paraná, cujo objetivo foi analisar como as práticas de violência aplicadas às pessoas LGBTQIA são manifestas no cotidiano escolar a partir da captação de falas espontâneas de educadores/as sobre a diversidade sexual e a homofobia. Em termos metodológicos recorreu-se a entrevistas semiestruturadas a 38 indivíduos que consideramos informantes-chave, como diretores/as, pedagogos/as e professoras. A análise de conteúdo foi orientada em "quem fala" e "com que finalidade fala", sendo que a partir das interlocuções dos sujeitos estabelecemos categorias que foram discutidas a partir dos Estudos de Gênero e dos Estudos Culturais. As principais conclusões apontam que vivemos um momento no qual, todos, somos agentes responsáveis por uma educação igualitária, que não comporta a ausência de discussões sobre diversidade sexual e de estratégias de enfrentamento à homofobia, portanto, o maior desafio que se apresenta na atualidade para nós educadores/as é o de abrir-se para esse debate.
\end{abstract}

PALAVRAS-CHAVE: Homofobia; LGBTQIA; Diversidade Sexual; Escola.

\section{DIRECTORS, PEDAGOGUES AND TEACHERS: KEY INFORMES OF THE INTERDISTS ON SEXUAL DIVERSITY AND HOMOPHOBIA AT SCHOOL}

\begin{abstract}
The present article presents partial results of an investigation about sexual diversity and homophobia centered in the school. The research was carried out in thirteen public high schools in different districts of the North of Paraná, whose objective was to analyze how the practices of violence attributed to LGBTQIA people are evident in the daily life of the school, through the capture of spontaneous speeches by educators about diversity And homophobia. Methodologically, we used semi-structured interviews with 38 individuals who we consider as key informants, such as directors, pedagogues and teachers. The content analysis was oriented in "who speaks" and "with what purpose it speaks", being that from the interlocuções of the subjects we established categories that were discussed from the Studies of Gender and the Cultural Studies. The main conclusions point out that we are living in a moment in which we are all agents responsible for an egalitarian education, which does not entail the absence of discussions about sexual diversity and strategies for coping with homophobia, and therefore the greatest challenge facing us today Is to open up to this debate.
\end{abstract}

KEYWORDS: Homophobia; LGBTQIA; Sexual Diversity; School.

\footnotetext{
${ }^{1}$ Professor Colaborador na Universidade Estadual do Paraná - UNESPAR. Doutor em Educação pela Universidade Estadual Paulista Júlio Mesquita Filho. E-mail: jr_oliveira1979@hotmail.com
} 


\title{
DIRECTORES/AS, PEDAGOGOS/AS Y PROFESORAS: INFORMANTES CLAVES DE LO ENTREDICHO ACERCA DE LA DIVERSIDAD SEXUAL Y LA HOMOFOBIA EN LA ESCUELA
}

\begin{abstract}
RESUMEN
Este artículo presenta resultados parciales de una investigación centrada en el ambiente escolar acerca de la diversidad sexual y la homofobia. La investigación tuvo lugar en trece escuelas públicas de enseñanza media de diferentes municipalidades del Norte de Paraná, Brasil, y su objetivo fue analizar cómo se manifiestan las prácticas de la violencia en contra de las personas LGBTQIA en el cotidiano escolar, a través de la recolección de hablas espontáneas de educadores/as acerca de la diversidad sexual y la homofobia. Metodológicamente, se hicieron entrevistas semiestructuradas a 38 individuos que consideramos como informantes claves, los/las que eran directores/as, pedagogos/as y profesoras. El análisis de contenido se orientó hacia "quién habla" y "con qué finalidad habla", y de las interlocuciones de los sujetos establecimos categorías que discutimos desde los Estudios de Género y los Estudios Culturales. Las principales conclusiones indican que vivimos en un momento en el que todos somos agentes responsables por una educación igualitaria, en el que no se puede permitir la ausencia de discusiones acerca de la diversidad sexual y de estrategias de combate a la homofobia y, por ende, que el desafío mayor de la actualidad para nosotros/as los/las educadores/as es el de estar abiertos/as a un debate como este.
\end{abstract}

PALABRAS CLAVE: Homofobia; LGBTQIA; Diversidad Sexual; Escuela.

\section{INTRODUÇÃ̃O}

Allport (1954 apud DOVIDIO, GLICK, RUDMAN, 2005), o fundador da teoria cognitiva do preconceito em sua obra The Nature of Prejudice, considera a discriminação e o preconceito como subprodutos inevitáveis do modo de pensar e (re)agir das pessoas, sustentado num ódio irracional nascido na ignorância e nas manobras ego defensivas de sujeitos com estruturas de personalidade fraca.

Para Hall (2006; 2007) e Silva (2007), essa temeridade, no que se refere à homossexualidade, estaria ancorada na desconstrução do binarismo tanto de gênero quanto de identidade sexual, que determinam as condições de masculinidade e feminilidade e exercício da sexualidade. Essa recusa deve-se à necessidade constante em impor qual sexualidade deve ser dominante, ou seja, a heterossexual e todo/a aquele/a que não se enquadra "[...] nesse esquema passa a ser considerado da ordem do 'desvio', do 'bizarro', da 'anomalia', das 'perversões', ‘patologias' [...]”' (SOUSA FILHO, 2013, p. 04), esquema fundador das violências contra pessoas Lésbicas, Gays, Bissexuais, Bigêneros, Travestis, Transexuais, Transgêneros, Queers, Questionadores/as, Intersexos, Indecisos/as, Assexuados/as e Aliados/as - LGBTQIA 
- ou seja, qualquer variação da sexualidade que atente contra a heterossexualidade compulsória permanece como um obstáculo ao pleno gozo de direitos desses sujeitos (BORRILO, 2009).

Esse sistema de opressão emerge nas mais distintas instâncias sociais, como na igreja, política, mídia, sociedade, escola etc. e se manifestam por meio de "[...] ações punitivas ou recuperadoras, de reclusão ou de regeneração, de ordem jurídica, religiosa ou educativa" (LOURO, 2009, p. 88), portanto, são práticas sociais e culturais herdadas historicamente que marcam cotidianamente essas instituições e desqualificam "o outro" enquanto sujeito de direito (HALL, 2006; SILVA, 2007; BORRILLO, 2009).

Quando o ambiente em que se manifestam tais atos de violência adquire um status de privacidade, como no caso da escola, essas ações se traduzem em situações limites que vão desde agressões físicas até as formas mais sutis, como as de violência simbólica sinalizadas em piadas, brincadeiras jocosas ou mesmo comentários e insinuações de desejo de afastamento de pessoas suspeitas de serem homossexuais (DINIS, 2011; BORGES, PASSAMANI, OHLWEILER, BULSING, 2011).

Outra face da pedagogia do insulto que atinge alunos/as LGBTQIA refere-se à negativa implementação de medidas de promoção do reconhecimento da diversidade sexual, em partes, sustentada na invisibilidade desses/as alunos/as. Essa forma de opressão tende a reforçar, neutralizar, naturalizar ou minimizar a homofobia, para não entrarem em conflito com a constituição de uma identidade heteronormativa (JUNQUEIRA, 2009a, 2009b).

A violência sistêmica ou ocultamento dela, a qual neste estudo chamaremos de LGBTQIAfobia ${ }^{\mathrm{i}}$, impacta diretamente na esfera dos sentimentos, da dignidade, do rendimento escolar, pois gera nas pessoas, que são alvo desses mecanismos, mal-estar, insegurança, angústia, isolamento e sofrimento. Movidas por esses sentimentos, as pessoas LGBTQIA podem apresentar dificuldades em suas relações sociais; terem seu rendimento escolar prejudicado, levando-as à evasão compulsória da escola; consequentemente impedir seu acesso a oportunidades de emprego ou promoção no ambiente de trabalho; aumentar sua vulnerabilidade ao uso de drogas, sujeição à prostituição e exposição a doenças venéreas além de influenciar em sua qualidade de vida e de saúde (BRASIL, 2011, p. 22).

Essa miscelânea de sentimentos adquire um poder ainda maior em atitudes, falas, silenciamento, gestos, no tratamento diferenciado dos/as professores/as que podem contribuir para que os/as próprios alunos/as LGBTQIA incorporem esses preconceitos e pensem a si 


\section{$e$-Curriculum}

mesmos/as como "realmente diferentes", ou nos/as demais alunos/as que passam a percebê-los como desiguais, portanto, passíveis de discriminação (FERRARI, 2000).

Diante dessas breves notas introdutórias, este artigo objetiva analisar como algumas formas de violência destinadas aos sujeitos LGBTQIA se manifestam na escola, a partir das falas espontâneas de educadores/as sobre aquilo que vivenciam, sentem e pensam sobre diversidade sexual e LGBTQIAfobia. Portanto, trazemos o recorte de dados de uma pesquisa desenvolvida em escolas da Rede Pública de Ensino Médio, de 13 Municípios do Norte do Estado do Paraná, da qual participaram 12 Diretores/as Escolares; 13 Pedagogas e 13 Docentes, que, após esclarecimento sobre a pesquisa, manifestaram interesse em participar do estudo mediante assinatura do Termo de Consentimento Livre e Esclarecido - TCLE.

Inicialmente, obtivemos informações de indicadores sócio demográficos, preenchidos pelo pesquisador que indagava os sujeitos por meio de um questionário estruturado, elaborado previamente pelo pesquisador. Um questionário estruturado é definido por Boni e Quaresma (2005, p. 73) como sendo aquele em que "[...] as perguntas são previamente formuladas e temse o cuidado de não fugir delas [...]”. Seguindo essas diretrizes, levantamos questões quanto a gênero, idade, turno e séries de atuação, escola que exerce a docência ou função administrativa/pedagógica, jornada de trabalho diária, formação acadêmica, tempo de magistério ou de função, dentre outras, por meio da aplicação desse questionário.

Sob anuência de cada participante, prosseguimos individualmente e em momentos distintos com a aplicação da entrevista semiestruturada, sendo esta gravada e posteriormente transcrita, composta por 21 perguntas, que levassem em conta a sequência de pensamentos dos/as entrevistados/as de forma que pudesse haver uma continuidade à conversação e às ideias baseadas em questionamentos que avaliavam o conhecimento sobre: diversidade sexual, homofobia e Kit de Combate e Prevenção à Homofobia do MEC, sendo que, para este momento, faremos um recorte discutindo resultados parciais obtidos sobre diversidade sexual e homofobia.

Optamos pela entrevista semiestruturada, pois, nesse tipo de investigação o/a pesquisador/a segue um conjunto de questões previamente definidas, porém realizadas em um contexto muito semelhante ao de uma conversa informal. O/A entrevistador/a atento/a dirige, nos momentos que achar adequado, a “[...] discussão para o assunto que o interessa fazendo perguntas adicionais para elucidar questões que não ficaram claras ou ajudar a recompor o 
contexto da entrevista, caso o informante tenha 'fugido' ao tema ou tenha dificuldades com ele" (BONI, QUARESMA, 2005, p. 75).

A análise de conteúdo foi orientada em "quem fala" e "com que finalidade fala". Para Moraes (1999), uma análise de conteúdo orientada a "quem fala" busca investigar o/a emissor/a da mensagem no contexto ao qual está inserido/a. Nesse caso, de certo modo, avança-se a hipótese de que a mensagem exprime e representa o/a emissor/a ou mesmo uma classe. Ao direcionar o estudo para o "com que finalidade" o/a pesquisador/a se questionará sobre os objetivos emitidos em uma mensagem, sejam explícitos ou implícitos. "Analisar a finalidade é novamente orientar-se para o emissor, mas no sentido de captar as finalidades com que emite uma determinada mensagem, sejam eles manifestos ou ocultos” (MORAES, 1999, p. 11).

Dessa forma, faremos inferências do texto daquele/a que emitiu a mensagem e com qual finalidade, por isso analisamos os discursos de diretores/as escolares, pedagogas e professoras/es considerando opiniões, conceitos, preconceitos, práticas intrínsecas ou extrínsecas sob o viés das seguintes categorias de análise: os "zarus" presentes nos discursos docentes; as diferenças na subversão das identidades; (des)valorizando as diferenças e a escola ditando comportamentos, as quais discutimos a partir dos Estudos de Gênero desenvolvidos por Louro $(2009,2010)$ e dos Estudos Culturais propostos por Hall $(2006,2007)$ e Silva (2007).

\section{OS “ZARUS” PRESENTES NOS DISCURSOS DOCENTES}

À escola é imputada a tarefa de "[...] redimensionamento, na construção e na reconfiguração dos valores e julgamentos morais atribuídos pelo senso comum às minorias, às diferenças e à diversidade de modos de estar no mundo" (FONTES, 2009, p. 99) e o reconhecimento da presença nesse espaço de alunos/as LGBTQIA é o primeiro passo na conquista da valoração desses sujeitos. Entretanto, a tarefa não é tão simples assim e tanto direção escolar, pedagogas e professores/as "[...] com distintas bagagens e modos de ver e viver o mundo podem não estar atrelados a uma perspectiva [...] [respeitosa] do exercício da sexualidade" (ABRAMOVAY, 2009, p. 196).

Evidentemente, os/as próprios/as profissionais “[...] nem sempre se mostram dispostos a fazer um diálogo mais aprofundado ou a adotar medidas que favoreçam o avanço dos direitos 


\section{e-Curriculum}

sexuais [...]" (JUNQUEIRA, 2009b, p. 173) e, “[...], portanto, não conseguem educar os/as estudantes para lidar com as diferenças" (ABRAMOVAY, 2009, p. 196).

A observação e a análise do cotidiano escolar revelam situações e procedimentos pedagógicos e curriculares estreitamente vinculados a processos sociais por meio dos quais se desdobra e aprofunda a produção de diferenças, distinções e clivagens sociais que, entre outras coisas, interferem na formação e na produção social do desempenho escolar (JUNQUEIRA, 2012, p. 65).

Os depoimentos coletados nessa pesquisa evidenciam que, mesmo a escola se mostrando como "[...] uma instituição fortemente empenhada na reafirmação e na garantia do êxito dos processos de heterossexualização compulsória e de incorporação das normas de gênero, colocando sob vigilância os corpos de todos/as [...]" (JUNQUEIRA, 2012, p. 66), diretores/as, pedagogas e professoras/es, com suas limitações em compreender conceitos vinculados à multiplicidade sexual, já precisaram em algum momento, no exercício do magistério, lidar com os efeitos da opressão destinada a esses/as alunos/as.

Indagados/as sobre a presença de alunos/as LGBTQIA no espaço escolar educadores/as, em certos casos, se desencontram em seus discursos dentro de uma mesma unidade educativa. Percebemos que aquele/a que desempenha uma função de comando, como é o caso da direção escolar, está atrelado/a apenas às questões administrativas, burocráticas e desvinculado/a do processo de formação da clientela escolar, portanto alheio à presença do público LGBTQIA, fato que reforça a invisibilidades desses/as alunos/as.

"Têm casos, assim, que você pode até imaginar que seja, mas nunca houve nenhum caso abertamente, ou falado sobre isso" [...] Olha, é como eu te disse, se existe a gente não sabe. Tanto é que a gente não tem recebido nenhuma reclamação [...] como não é um assunto que a gente vive constantemente com isso, ou então fica meio afastado das nossas atividades, então a gente fica meio leigo nessa situação" (Casimiro, diretor, grifo nosso).

Constatamos que, aquelas que desempenham o papel de orientação, coordenação como os/as profissionais pedagogos/as têm consciência da presença de um contingente de identidades no âmbito escolar, porém assumem a vulnerabilidade em arrazoar qualquer discussão sobre a temática.

"Ah, a gente tem, tem sim. Tem conhecimento [...] Alguns se declararam. Outros não, né”. [...]. Mas, por tudo que nós fazemos, a gente vê que ainda é 
muito pouco o resultado em relação a isso sabe, parece que é algo difícil de lidar" (Cacilda, pedagoga, grifo nosso).

As pessoas que desempenham a docência convivem cotidianamente com alunos/as LGBTQIA, no entanto, diante de situações que demandam uma atuação proativa, possuem dificuldades ou até desconhecem maneiras apropriadas de abordar a discussão.

"Tenho, eu trabalho com eles sim" [...] Entrevistador: Você já comentou isso com o diretor? Carmem: Não. Nunca houve, necessidade" (Carmem, professora, grifo nosso).

Fazendo uma paráfrase à fábula dos "Três Macacos Sábios”, conhecida como "Os Três Macaquinhos" localizados à esquerda da porta do Santuário Toshogu, um templo do século XVII, localizado na cidade de Nikko, no Japão, cuja origem é baseada em um trocadilho japonês e seus nomes são: kizaru (aquele que tapa os ouvidos), mizaru (o que cobre os olhos) e iwazaru (quem tapa a boca). O sufixo zaru presente nos nomes está ligado à negação e seu significado é traduzido como: "não ouça o mal, não veja o mal e não fale o mal”. É uma forma de lembrar que, se os/as homens/mulheres não ouvissem, não olhassem e não falassem o mal alheio, teríamos comunidades pacíficas com paz e harmonia (OLIVEIRA JR, 2013).

Quando transpomos para o debate da diversidade sexual e da LGBTQIAfobia, os zarus também se fazem presentes, porém, ao contrário da lenda japonesa em que a negação está localizada do lado de fora dos portões, na escola os interditos estão situados intramuros e, semelhante aos três primatas, o/a diretor/a escolar é aquele que não ouviu, a pedagoga não viu e a/ professor/a não quer falar. Recursos, esses, empregados como estratégia de pacificação e convivência harmônica com a heteronormatividade ${ }^{\mathrm{ii}}$ e seus/suas defensores/as.

"Tudo nós temos que estar amparado pela Lei, pelo Núcleo, porque isso aqui é uma escola estadual e não particular. Não depende de mim, não depende de professor, não depende de pedagogo" (Casimiro, diretor, grifo nosso),

Contudo, em continuidade ao discurso, observamos na fala da pedagoga que:

\footnotetext{
"Isso já é conversado com os professores, se surgiu a necessidade, para o trabalho aqui, se achar que não tem condições traga pra nós e nós vamos ver se nós mesmo pedagogas temos condições de fazer isso, mas também temos a liberdade de chamar um profissional, dependendo da situação, para falar com os alunos" (Cacilda, pedagoga).
} 
O que deveria ser uma unidade coesa de combate às situações de preconceito, com as quais essas pessoas convivem cotidianamente, nos deixam dúvidas quanto à coletividade e evidenciam tanto a ausência de diálogo na produção de estratégias de enfrentamento que reforça a subjetivação.

Estabelecendo um paralelo, para Foucault (2007, p. 44), a educação, ao mesmo tempo em que permite, impede o reconhecimento das múltiplas identidades por meio de " [...] linhas que estão marcadas pela distância, pelas oposições e lutas sociais. Todo sistema de educação é uma maneira política de manter ou de modificar a apropriação dos discursos, com os saberes e os poderes que eles trazem consigo" e, nesse contexto, se materializam algumas inferências: será que a direção escolar se mantém alheia a essa discussão por acreditar não ser de sua responsabilidade e permanece no aguardo da corporificação da situação tomando uma posição coletiva de salvaguarda?

"Olha...a gente até tem. Desconfia assim que tenha, mais não, nenhum assumido que tenha vindo conversar ou que a família tenha se pronunciado, nessa escola não" (Cecília, diretora).

Podemos pensar que a orientação escolar entende a presença de alunos/as LGBTQIA e a influência da opressão a que são submetidos/as, mas não sabe como agir ou se ocupa de outros afazeres?

"Porque têm tantos trabalhos burocráticos pra fazer que não dá tempo de acudir esse lado. Então é complicado, na escola é muito complicado esses fatores, de tá trabalhando com esses tipos de diversidade" (Khadijah, pedagoga, grifo nosso).

O corpo docente habituou-se com a multiplicidade de condutas sexuais e prefere acreditar que todos/as são iguais e trata-os/as indistintamente?

"[...] eles são recebidos como qualquer outra pessoa, porque não deixa de ser, normalmente" (Anésia, professora, grifo nosso).

"[...] os professores em si, é... trata como uma pessoa normal, como as outras. Assim, não faz diferença" (Beatriz, professora, grifo nosso).

"[...] a escola trata como a melhor forma possível. Trata bem, normal, como trata todos os demais alunos, nê" (Catarina, professora, grifo nosso). 
"Normal, normal, como outro qualquer. O tratamento que a gente vê em sala de aula pra mim é normal, não tem diferença nenhuma, nem entre os colegas não" (Marilyn, professora, grifo nosso).

Continuamos a nos interrogar sobre a o fato desses/as alunos/as se fazerem presentes na escola e assumirem sua condição, como são tratados/as pela comunidade escolar?

"[...] muitas vezes também os professores fingem não ver, e eu acho, que nós, nós a escola deveria ter um outro olhar, um olhar assim, de pelo menos conversar, de ter liberdade pra conversar com esse aluno, de falar [...] muitas vezes, eles fingem que não veem. Pra quê?? Pra não entrar em contradição" (Aspásia, pedagoga).

“Ainda há resistência tanto de alunos, quanto funcionários, como professores pra tratar disso como algo tranquilo, como um direito e não como uma discriminação" (Fidel, diretor).

"Apesar do trabalho que a escola vem realizando em atender esses alunos, a gente observa que em sala de aula ainda tem muito preconceito, tem muita discriminação" (Brida, pedagoga).

É necessário enfatizar que profissionais da equipe diretiva, pedagógica e docente carecem de envolvimento na construção do

[...] currículo escolar, objetivando a aprendizagem dos/as alunos/as. Assim, eles/as podem estar propiciando que as discussões relacionadas a essas temáticas estejam presentes nas escolas, possibilitando espaços de interlocuções e auxiliando na elaboração de projetos relacionados ao assunto. Esses/as profissionais devem possibilitar a inclusão das questões sociais no currículo escolar como, por exemplo, a sexualidade, a diversidade, a homofobia, entre outras. Nesse sentido, não só os/as professores/as devem estar envolvidos nas discussões relacionadas à sexualidade, todos/as os/as profissionais das escolas, de uma maneira ou outra, podem possibilitar que essas questões sejam debatidas (BARROS; RIBEIRO; QUADRADO, 2011, p. 188).

Esses/as profissionais precisam voltar a sua atenção quanto à sua função social, pois é a partir da subjetivação e do "assujeitamento", que alunos e alunas LGBTQIA

[...] vão se tornando cada vez mais vulneráveis diante da vida, perdendo a força do questionamento e da crítica. Ficam à mercê de qualquer forma de desrespeito, de abandono e descaso dos outros, das famílias, das escolas, dos currículos, enfim, das políticas públicas que possam promover a inclusão e o direito a ter direitos, logo, de exercer a cidadania (PERES, 2009, p. 239).

O alheamento por parte da escola sobre a (re)produção das diferenças tende a gerar uma hierarquia e exclui do convívio diário aqueles/as que transgridem identidades fixas, além de 
desestimular a permanência desses/as alunos/as por meio de um sistema repressivo de expulsão compulsória.

"[...] a gente percebe que a pessoa que tem oportunidade ela vai embora até da cidade. Assim, por ser um município muito pequeno, todo mundo conhece todo mundo, então a grande maioria que tem isso [homossexualidade] daí eles acabam, se eles têm um poder aquisitivo melhor eles vão embora do município pra estudar, pra trabalhar, pra ter a vida fora do município" (Mercedes, professora, grifo nosso).

Observa-se que para esses indivíduos uma das soluções é a saída da escola ou evasão compulsória - pois não não há possibilidade de escolha e de permanência, colocando-os para fora do sistema, através de um contínuo e sistemático jogo de ações repressivas. Essas relações opressivas tendem a causar "[...] constantes trocas de estudantes de sala, mudanças de escola, abandono e reprovações, com impacto direto no fracasso escolar de alunos homossexuais ou tidos como homossexuais" (ABRAMOVAY, 2009, p. 204).

\section{ELES/AS SÃO DIFERENTES: SUBVERTENDO IDENTIDADES}

Congregada às caraterísticas das configurações familiares, a possibilidade de alguma alteração genética, hormonal ou desvio de personalidade, os/as docentes se julgam capazes de detectar a homossexualidade em alunos/as, desde a mais tenra idade ao sintomatizá-la pela presença de comportamentos considerados típicos do gênero oposto (meninos mais afeminados e meninas mais masculinizadas, por exemplo).

"Pra mim não é doença não é nada. É uma genética que... é uma... nasceu diferente [...]. Não é porque eu... é uma opção minha. É porque é a genética. Ela vem diferente" (Cecília, diretora).

"Muitas vezes a pessoa é homossexual, mas ela não queria ser homossexual né. Então é uma coisa assim hormonal mesmo nê" (Catarina, professora).

"[...] normalmente a gente vai lá e tenta passar que é normal, que cada um... que eu tento passar que é uma opção, que não é sem-vergonhice, que nasce assim. Assim como ele nasce gostando de menina, ou a menina nasce gostando de menino, esse nasce gostando do mesmo sexo" (Napoleão, diretor).

"Muita gente acha que é sem-vergonhice, que a pessoa tá ali que ela quer se aparecer que isso aí é atitude de aluno que quer se aparecer mesmo, quer ser diferente perante os outros" (Mercedes, professora). 
"Quando geneticamente você nasce daquele jeito, tudo bem. Mas têm outros pessoal que acha que depois que fica adulto aí quer ficar diferente, mas não é né?" (Beatriz, professora).

O recurso a mitos fundadores faz com que a identidade heterossexual habite o imaginário coletivo da "naturalidade" e as características fenotípicas, genotípicas e hormonais herdadas com o nascimento impelem a sociedade a perceber a coexistência estrita de machos e fêmeas. Fatores esses que conduzem o reconhecimento da sexualidade como uma consequência biológica, partilhada por todos/as e sem qualquer relação com a sua história, cultura e sociedade, nas quais os sujeitos estão inseridos. Tal aspecto torna a sexualidade universal e vivida de maneira singular por todos/as. No entanto, não se encontra na literatura uma causa biológica às suas variações, ou melhor dizendo, não existe nenhuma conclusão que possa ser considerada significante, conclusiva sobre o nascimento da homossexualidade (FURLANI, 2007, SILVA, 2007).

A ideia de que a causa estaria na matriz hormonal foi, sem dúvida, a primeira hipótese levantada, uma vez que a biologia conhece a importância dos hormônios na determinação dos caracteres sexuais físicos dos indivíduos e das alterações morfofisiológicas decorrentes de mudanças nas concentrações hormonais, principalmente ao nível embrionário. Entretanto, não se conseguiu obter um quadro de variações hormonais em amostragens adultas de indivíduos com práticas que permitisse conclusões que induzissem a uma relação casual (FURLANI, 2007, p. 157-158).

Assim como a ciência não obteve uma resposta plausível sobre a interferência hormonal nesse processo, não há evidências definitivas de que a manifestação da sexualidade atuaria em nível neurofisiológico (FURLANI, 2007). Diante da desmistificação do caráter biologizante da homossexualidade, é necessário buscar novas respostas para caracterizá-la. Incorporada a essa visão, educadores/as criam e recriam modelos de alunos com características gays, tais como: “[...] teriam voz fina, trejeitos, gestos, jeito de falar, de olhar, de andar diferentes dos heterossexuais [...]" e que alunas "[...] lésbicas teriam um comportamento "agressivo" e poderiam ser reconhecidas "pelo cabelo curtinho", "estilo de homem", "jeito de se sentar", "traços de homem" [...]" (REPROLATINA, 2011, p. 38-39).

"[...] eu trabalhava num Centro de Educação Infantil e alunos que hoje estão entrando nos 18 anos que estão optando pela [...] homossexualidade ou alguma coisa parecida, eles tinham esses sintomas, eu falo. Apresentavam sintomas disso quando tava lá na Educação Infantil. Entrevistador: O que seriam esses sintomas? Nefertiti: Eu ficava preocupada né, se colocava uma 
música livre, essas crianças queriam aquela música assim, sabe? [a entrevistada gesticula desmunhecando a mão]. Não que eu tenho preconceito, mas, levando mais pra esse tipo de música sabe? Que tinha que ficar rebolando, mais de ficar demonstrando o corpo. Às vezes enrolava a blusa e colocava embaixo aqui assim [a entrevistada demonstra como se prendesse a camiseta ao sutiã]. Gostava muito de brincar, quando menino, tava sempre no meio de meninas, com boneca” (Nefertiti, professora, grifos nossos).

As possíveis "confusões" dentre as incontáveis crianças ao "[...] misturar os dois mundos (o masculino e o feminino) são interpretadas pelo olhar atencioso das instituições, como um indicador de uma homossexualidade latente" (BENTO, 2011, p. 552). Nesses casos, é preciso ater-se ao fato de que, embora a criança manifeste preferências por brinquedos considerados masculinos e/ou femininos, ela brinca indistintamente com bolas, bonecas, panelinhas, casinhas, carrinhos. Na Educação Infantil, ela desconhece as práticas e táticas culturais que sinalizam a diferença por meio dos objetos que devem ser utilizados para cada gênero. Algo que aos poucos, como afirma Foucault (2004), será vigiado, corrigido e punido, já que o corpo "[...] precisa ser esculpido, enquadrado, domesticado, resguardado, produzindo identidades não apenas demarcadas pelas diferenças, mas também pela hierarquia" (SALVA; STIMAMIGLIO, 2011, p. 1363).

"[...] A gente tentava às vezes e a gente percebia que a família tinha esse histórico também. É uma família perturbada, coisas assim, com problemas, muitos problemas. Desde pais separados, mães que apanhavam. Então ficava aquela estrutura que hoje eu penso, ficava a mãe, a irmã e o menino em casa. Então isso eu vejo que dava uma norteada pra isso. Percebo hoje em dia não estando lá como era a história daquele aluno, daquela criança. [...] Sempre tem a figura de mãe. Figura de mãe, figura de irmã, figura de mulher. Entendeu? [...] Eu acho que pode ajudar. Pode levar pra isso" (Nefertiti, professora, grifos nossos).

Nesse contexto, cabem duas discussões, em primeiro lugar, ao problematizarmos que as identidades são formadas ao longo do tempo por uma sucessão de processos conscientes ou inconscientes, podemos considerar que elas serão sempre incompletas, pois estão em permanente construção e reconstrução, no entanto, determinados/as educadores/as assimilam uma fase da vivência humana, o ambiente, as roupas, assim como o jeito ou o comportamento como indicadores da homossexualidade. Não é preciso se assumir homossexual publicamente para que a discriminação aconteça, pois o aparentar ser homossexual, ou melhor, aquilo que o/a outro/a acha já é motivo suficiente para justificar as chacotas, os insultos, as humilhações e o olhar de indiferença (HALL, 2007; SILVA, 2007; ABRAMOVAY, 2009). 
Em segundo lugar, sem dúvidas, fatores externos e internos têm ocasionado comportamentos adaptativos de uma variedade infinita, resultado das transições ocorridas nos âmbitos cultural, econômico, transgeracional, político e social e na história de seus membros, que têm afetado a instituição familiar de uma forma, talvez, jamais vista na história (OLIVEIRA JR, 2016). Hoje, principalmente, o que temos são "famílias" que passaram a refletir as mudanças históricas que ocorreram na sociedade “[...] nos papéis e nas relações em seu interior, bem como alterando sua estrutura no que diz respeito à composição [...]" (SIMIONATO; OLIVEIRA, 2003, p. 58).

Como não podemos falar em uma falência absoluta do sistema patriarcal, no qual há o predomínio masculino sobre as mulheres, precisamos

[...] reconhecer que suas leis e noções internas não dão mais conta das demandas relacionais criadas nas sociedades liberais e democráticas, onde os cidadãos criam e recriam mais livremente suas experiências afetivas [...]. Neste sentido, o declínio do patriarcado tem se mostrado evidente em muitos contextos relacionais, dos quais a família é o mais visível, mas ele permanece ainda com certa força no imaginário social de sociedades [a incluir a escola] ainda frágeis do ponto de vista do favorecimento da expressão livre de seus cidadãos. [...] Vivemos, assim, muitas contradições: na prática acompanhamos a diversificação dos modelos familiares, mas em tese continuamos, em grande medida, a considerá-los a partir de concepções que se tornam cada vez mais obsoletas (PASSOS, 2005, p. 33).

Porém, assim como a reprodução do relato da professora Nefertiti, é no cotidiano escolar que se presenciam as práticas mais excludentes daqueles/as que desatendem padrões normativos, ao privilegiar um estilo particular de exercício de paternidade/maternidade e que poderá enfraquecer a autonomia e a liberdade dos pais e mães por meio da assunção de um arcabouço heteronormativo num processo colonizador de ordenamento da(s) identidade(s) e das representatividades impostas pelas condutas normalizadoras (BUTLER, 2010).

Como defende Carvalho (2004), essa tendência impõe tensões, “em primeiro lugar, ela adota um modelo único de família: afluente, do qual se distancia um grande número de famílias [...]” (p. 149). E também porque “[...] permanecem implícitas as relações de classe e, sobretudo de gênero, que compõem os modelos de família que conduzem ao sucesso ou fracasso escolar" (CARVALHO, 2000, p. 144).

Esses fatores ganham maior notoriedade quando são relacionados à estrutura familiar, que tende a ser apontada como um ambiente propício para a promoção da homossexualidade, 


\section{e-Curriculum}

quando ausente de figuras representativas do gênero oposto, já que a família pode ser vista como espaço privado, no qual sistemas de valores e crenças são internalizados, juntamente com os papéis de construções de gênero, o que involucra os preconceitos e tabus que são transmitidos intergeracionalmente, e que são permanentemente construídos, desconstruídos e reconstruídos, refutados ou reafirmados (SANTOS, BROCHADO JUNIOR, MOSCHETA, 2007).

Dessa forma, educadores/as tendem a alegar que a família tem estado por trás do sucesso e tem sido culpada pelo fracasso escolar, acusando determinados modos de famílias pelos comportamentos dos estudantes, além de possuírem crenças pessimistas em que determinadas organizações familiares, caracterizadas como desorganizadas, desviantes e instáveis, são consideradas as grandes responsáveis pela manutenção ou definição de uma identidade sexual normalizadora ou desviante (CARVALHO, 2000; 2004).

Retomando nossa discussão anterior, ao indagar profissionais do magistério se em sua escola havia algum/a aluno/a Lésbica, Gay, Bissexual, Travesti ou Transexual e como eram vistos/as e identificados/as pela comunidade escolar, a discussão assume tais contornos:

"Não propriamente eu, a minha pessoa, as pessoas né. Os comentários das pessoas falando, determinadas pessoas às vezes comentam a forma de agir, entende, o tratamento com outras pessoas. Talvez por esse motivo se ache que pode ser" [homossexual] (Casimiro, diretor, grifo nosso).

"Olha eles [homossexuais] têm um agir diferente. Eles têm um vestir diferente. Têm interesses diferentes, nesse aspecto" (Kate, pedagoga, grifos nossos).

"Eu percebo pela maneira de agir, pela maneira de falar, pelos pensamentos, pelos atos" (Cecília, diretora, grifos nossos).

" $O$ jeito de andar, o jeito de falar, o relacionamento com os outros alunos, então é isso que eu percebo" [em alunos/as LGBTQIA] (Margot, diretora, grifo nosso).

A escola apresenta uma tendência a definir o gênero de seus componentes através da vestimenta que compõe o ideário masculino e/ou feminino, dos gestos, dos modos e comportamentos, ou seja, de um estilo de ser e portar definido como uma conduta apropriada para homens e para mulheres. Postos em ação, esses sinais exteriores irão estabilizar e dar visibilidade ao corpo (BENTO, 2011), o qual “[...] delimita espaços servindo-se de símbolos e códigos, ela afirma o que cada um pode (ou não pode) fazer, ela separa e institui. Informa o 'lugar' dos pequenos e dos grandes, dos meninos e das meninas" (LOURO, 1997, p. 58). 
"[...] têm meninos que eles só ficam junto com as meninas, difícil ele se entrosar com a turma dos meninos" [parece ser homossexual] (Mata, pedagoga).

"[...] tenho uma aluna lá, [...] que ela só gosta de coisas de meninos, que ela só fica com os meninos, que ela bate nos meninos, entendeu?" [ela pode ser lésbica] (Maria Quitéria, diretora).

"[...] a gente percebe no comportamento, percebe até na maneira de andar, de se vestir, de falar, né, essas características e outras" [são indicadores de uma possível homossexualidade] (Khadijah, professora).

"[...] a voz dele era um pouco mais fina. Muito educado [...] ele era diferente dos outros meninos. Ele trata as meninas muito bem" [são fatores que evidenciam uma possível homossexualidade] (Clarice, professora, grifo nosso).

A rotulação de crianças sensíveis, tímidas e estudiosas como possíveis homossexuais, mesmo sem que estas tenham a compreensão do significado de homossexualidade ou mesmo sem qualquer inclinação para o homoerotismo não é um processo livre de traumas (BORGES, PASSAMANI, OHLWEILER, BULSING, 2011). Essas características propulsionam atitudes homofóbicas ancoradas “[...] normalmente, às maneiras de agir e aos objetos considerados próprios ao universo do gênero oposto", tanto por alunos/as quanto pelos/as próprios/as educadores/as (ABRAMOVAY, 2009, p. 197) “[...] sendo que o que mais perturba quem não é gay não é a forma de vida gay, e sim os atos sexuais [...]”, propriamente ditos (FOUCAULT, 2000, p. 39).

Assim, a escola constrói dentro do processo educativo, independente da modalidade de ensino, "os contornos demarcadores das fronteiras entre aqueles que representam a norma [...] e aqueles que ficam fora dela, às suas margens" (LOURO, 2010, p. 15), por um coletivo representativo ou por cuidados físicos, exercícios, roupas, aromas, adornos, que, registrados nos corpos, reproduzem as diferenças. "Treinamos nossos sentidos para perceber e decodificar essas marcas e aprendemos a classificar os sujeitos pelas formas como eles se apresentam corporalmente, pelos comportamentos e gestos que empregam e pelas várias formas com que se expressam" (LOURO, 2010, p. 15).

Tal caracterização independe da idade em que se encontra o/a escolar, uma vez que o/a aluno/a na Educação Infantil já tende a ser apontado/a e rotulado/a como sendo uma pessoa LGBTQIA. Mesmo que esse/a aluno/a não tenha a menor noção de suas condutas sobre sua 
sexualidade. Sobre ele serão redobrados os cuidados e a vigilância. Porém, há de se tomar cuidado ao caracterizar esse/a aluno/o uma vez que essa identificação o/a acompanhará por todo o seu processo de formação.

"[...] nós temos uma faixa etária, onde estão se descobrindo, onde estão de repente você acha que é, mas, às vezes, o próprio aluno ele não se achou ainda, ele não se vê ainda, então a gente tem que ter assim, muito tato quando você vai lidar, né, porque de repente você não pode falar pro... pra pessoa aquilo que ela ainda não sabe dela mesma, né" (Carlota, diretora).

Como nem todas as atitudes são providas de precauções, as coisas se complicam ainda mais com o avançar dos estudos, quando alunos/as se percebem com “[...] interesses ou desejos distintos da norma heterossexual. A esses restam poucas alternativas: o silêncio, a dissimulação ou a segregação" (LOURO, 2010, p. 27).

A vivência em um lugar heteronormatizado,

[...] pode obrigar o sujeito ao jogo dissimulado da duplicidade. As pessoas encontram-se no "entre-lugar": aquele que traz para as suas práticas, a sensibilidade e os saberes das identidades que acumulam, mas, por conhecer os códigos predominantes da escola, optam por manter-se, ao olhar do outro, nas identidades legitimadas e reconhecidas para esse espaço. Esse quadro explica a astúcia e o cuidado para apreciar, ouvir, sentir e tocar as inúmeras situações em que as homossexualidades são visibilizadas, ou então, conhecendo seus limites, silenciadas momentaneamente (CAETANO, 2008, p.161).

Tais aspectos conduzem alunos/as LGBTQIA a vivenciarem seus desejos na clandestinidade ou mesmo a subvertê-lo, impedindo-os/as de realizarem suas aspirações sentimentais de forma plena.

\section{4 (DES)VALORIZANDO AS DIFERENÇAS}

Símbolos e espectros do pós-modernismo assombram agora “[...] lugares anteriormente sagrados pelos quais nossa própria geração uma vez se movimentou com grande confiança, como tinha feito à geração antes de nós. Agora as fundações tremem" (GREEN, BIGUM, 1995, p. 213), com isso a escola tende constantemente a buscar sustentações históricas de negação da pluralidade sexual. 
"Então os professores, são de uma época que veio os professores mais velhos, veem isso como uma agressão aos conceitos morais né, que isso vai causar, como eu falo...não um mal, mas é visto como um mal" (Nefertiti, professora, grifos nossos).

"Eu tenho aqui professores com muitos anos de carreira, que ele é daquela época assim sabe, que não aceita esse tipo de coisa. Então ele bate um pouco de frente" (Natália, pedagoga, grifo nosso).

Quando nos referimos à sexualidade, é válido ressaltar que é comum professores/as e alunos/as serem de gerações distintas, uma vez que, "ao longo da vida profissional, vai se alargando a distância entre a geração e o contexto moral em que o professor [a professora] foi criado [a], e as novas gerações e os novos contextos morais nos quais nossos alunos vivem e dos quais retiram seus valores" (SEFFNER, 2009, p. 131).

É imperioso pensarmos que os sentidos elaborados em tempos e lugares específicos não dão mais conta de aspectos da atualidade, ao assumirem foros de verdade impressos e expressos na linguagem em grande parte justificados pela tradição, memória, história, do "sempre foi assim" e "será sempre assim"; e, nesse ciclo de "[...] repetição, criam constantemente o solo sobre o qual se apoiam, ressematizando as "verdades" historicamente produzidas, como a expressão de uma realidade universal e/ou natural [...]" (SWAIN, 2009, p. 123) reprodutora, rígida, imutável e permanente.

Essas inúmeras e "[...] infindáveis repetições funcionam como citações, e cada ato é uma citação daquelas verdades estabelecidas para os gêneros, tendo como fundamento para sua existência a crença de que são determinados pela natureza" (BENTO, 2011, p. 553).

A escola enquanto agente de transformação precisa ter em vista que o futuro pertence aos/às jovens e à juventude que já o habita, em todos os sentidos. A questão central é: não deveríamos ser nós os/as que estamos sendo, assim, cada vez mais, transformados/as em "outros/as", com nossos poderes e conceitos se desvanecendo, no momento exato em que os exercemos nos sentirmos cada vez mais estrangeiros/as em nossas próprias salas de aula ou em nossos saberes (des)constituídos? (GREEN, BIGUM, 1995).

\section{ALUNOS/AS LGBTQIA: "SÃO ÓTIMOS, DESDE QUE SAIBAM SE COMPORTAR"}

Caracterizados/as como desviantes, apontados/as como ilegítimos tanto alunos quanto alunas, muitas vezes, sem quaisquer inclinações para o homoerotismo ou mesmo, 
assumidamente homossexuais são isolados/as na escola em atividades curriculares e no recreio, porque sendo meninos tinham mais afinidades com as meninas do que com os meninos e sendo meninas tinham mais intimidades com meninos do que com as meninas.

"Eles são excluídos muitas vezes do grupo de amizade, sim! E eu acho que isso interfere, sim, no processo. Por exemplo, você vai fazer um grupo de pesquisas, tem grupo que não aceita. Têm outros grupos que já aceitam tranquilamente. Então ele fica excluído porque não é todos que vão aceitá-lo, então ele fica excluído do grupo, a gente percebe isso" (Faustina, pedagoga).

"Ah, eu acho que afasta. Não são todos, lógico que tem gente assim né. Porque têm alunos que têm essa forma de vida, mass alguns não transparece. Têm alguns que já gosta mais de soltar. Então a pessoa evita na escola e atrapalha bastante" (Beatriz, professora).

"Os próprios colegas da sala meio que excluíam, sabe, não vou sentar perto, não vou conversar, não vou me misturar" (Maria Quitéria, diretora).

"Existem alunos que têm ainda esse preconceito que evitam" (Anésia, professora).

"Não querendo fazer trabalho com ele, entendeu, deixando ele, excluir ele mesmo da participação em grupo. Porque ele acha que se ele vai fazer com ele uma atividade, qualquer coisa, então os outros alunos estão rotulando ele que ele está tendo um caso com aquele, então esse fato é, eles discriminam mesmo em sala de aula, os próprios alunos" (Khadijah, professora).

O niilismo imposto a alunos/as LGBTQIA é referendado pelo corpo docente e administrativo das escolas e para Ferrari (2000) é muito comum encontrar nas falas dos/as professores/as que esses/as alunos/as

"[...] têm que se dar ao respeito", tentando com isso justificar suas atitudes de discriminação e as brincadeiras com eles a partir dos próprios homoeróticos. Quer dizer: como eles não se dão ao respeito podem ser objeto de brincadeiras, que demonstram todo tipo de discriminação, preconceito e exclusão (p. 1112).

Essa manutenção e regulação dos corpos por meio da disciplina, discutido por Foucault (2004), é evidenciado na preleção de professoras ao entenderem que determinados comportamentos e vestimentas são uma afronta à vida cotidiana da escola. O modo como alunos e alunas devem se comportar é correspondente a um laborioso aprendizado sociocultural que os/as ensina a agir conforme as prescrições de cada gênero. Há uma expectativa em relação à maneira de como alunos/as devam se portar, “[...] andar, falar, sentar, mostrar seu corpo, 
brincar, dançar, namorar, cuidar do outro, amar etc.[...]" (PARANÁ, 2009, p. 40) e, conforme o gênero, há a inculcação laboriosa de modos específicos de como, na vida exterior ao espaço escolar, essas pessoas deverão executar seu trabalho, se relacionar com outras, reproduzir as maneiras de ser homem e mulher como "[...] dirigir um carro, gastar dinheiro, ingerir bebidas, dentre outras atividades" (PARANÁ, 2009, p. 40).

A manutenção e regulação dessa normalização é constantemente vigiada e punida quando transgressora e

[...] não são apenas os alunos os que vigiam cada garoto "afeminado", mas sim a instituição inteira. E todos o fazem à medida que, de maneira capilar e permanente, controlam os demais e a si mesmos [...] [quando a professora chama atenção ao modo de se vestir, se portar e agir de alunos/as LGBTQIA] costuma configurar um gesto ritual por meio do qual seu alvo é desqualificado ao mesmo tempo em que seu enunciador procura se mostrar como um indivíduo perfeitamente adequado às normas de gênero [o/a professor/a sentese] um emissor institucionalmente autorizado, orgulhosamente bem informado pelas normas de gênero (JUNQUEIRA, 2012, p. 73).

Vale ressaltar a existência das múltiplas facetas de exercício das masculinidades e feminilidades, porém, durante nosso percurso pelas escolas, assim como Junqueira (2012, p. 73), “[...] notamos facilmente a intensa generificação dos seus espaços e de suas práticas, e o quanto as fronteiras de gênero são obsessiva e binariamente demarcadas [...]”.

"Porque, o homossexual menino, o homossexual dentro da sala de aula, tem que manter uma postura de respeito [...]. E, às vezes, com que houve reclamação do homossexual dentro da sala de aula foi por exagero por parte do homossexual, no seu comportamento, nos seus trejeitos, na linguagem, às vezes, muito vulgar e que chocava os alunos" (Cassandra, pedagoga, grifo nosso).

"É claro que se ele é homossexual sabe indecente você não vai gostar" (Carlota, diretora, grifo nosso).

"Eu acho que essas crianças precisam de muita orientação, porque o maior problema do preconceito que elas enfrentam é por falta de orientação, eu acho que é falta de orientação de saber como se comportar, de saber lutar pelo que deseja mas de uma forma sempre discreta. Eu gosto de ser discreta entendeu? Eu gosto de lutar, amparada do que me convém e conseguir as minhas coisas sem escândalo. Eu não gosto de muito escândalo, tem gente que gosta, eu não [...] a menina, por exemplo que é lésbica, lésbica, ela não sabe, ela não tá sabendo se comportar dentro da escola, então ela tá tendo atitudes que um outro casal, um exemplo né, não teria, um outro casal de namorados talvez não teria. E o professor, ele coloca aquilo ali como um enfrentamento, né, um confronto" (Aspásia, pedagoga, grifos nossos). 
"Porque têm muitos casos não sei por que, talvez a Psicologia explique, mas eles têm atitudes muito, como que eu digo? Umas atitudes assim de querer mostrar muito o que é. Sabe, querem se libertar muito. Então às vezes gera tudo isso, aí eu aconselho que eles tenham um comportamento normal como os outros, que tenham suas opiniões, que falem o que pensam, mas que na verdade, têm que respeitar os deveres como o dos outros né" (Brida, pedagoga, grifo nosso).

Atitudes, comportamentos, maneira de agir, como se vestir, dentre outras manifestações pessoais do exercício da identidade de gênero são alvos de intervenção por parte de educadores/as, com o propósito de naturalizar e subverter condutas culturais de como ser homem ou mulher. Tais práticas são arbitrariamente empregadas à serviço da consolidação do processo de heteronormatização, já que em grande parte

[...] a "aceitação" a alunos homossexuais é condicionada - eles podem ser gays ou lésbicas, desde que não pareçam, ou seja, uma vez que não incomodem os olhos dos outros. Uma inclusão onde a condição é que eles abram mão de suas identidades e se enquadrem em determinados padrões de comportamento; padrões estes que não têm nada a ver com o papel de um aluno - se comportar, fazer o dever, estudar, etc. - mas com papéis de gênero. Padrões de gênero que não constam em nenhuma lei ou norma escolar. Padrões de gênero que são acriticamente reproduzidos pelas escolas e estão baseados tão somente nas concepções pessoais dos educadores. Obrigar um aluno ou aluna a modificar o seu jeito íntimo de ser, de falar, de se fazer bonito para poder estudar, é condicionar um direito que é incondicional. É abuso de poder. É desrespeito [...] (BORTOLINI, 2008, s/p).

Essa postura indica que o educador ainda não entendeu que a identidade de gênero daquele/a aluno/a não é uma brincadeira, mas faz parte da construção da sua própria personalidade e identidade.

"No início ele quis vim é travestido mesmo né, com roupas bem extravagantes, assim usando a maquiagem forte. Mas aí a gente conversou, orientou que aqui era um espaço escolar, ele podia usar maquiagem e tudo, mas que ele viesse de uniforme igual os outros alunos né? Aí, quanto a isso ele entendeu bem, foi tudo bem" (Ruth, pedagoga).

"De repente ele assumiu, né, começou a vim, é... a se vestir igual travesti, vestido de mulher, usar pinturas... e aí começou o preconceito que vivemos" (Rosa, professora).

É fato que educadores e educadores sentem-se afrontados/as com o desatendimento da pedagogia da sexualidade e se julgam capazes, em determinados casos, de refrear um/a aluno/a 
pela forma de se vestir, se portar, agir e até de quem gostar e/ou se relacionar por "[...] sentirse um emissor institucionalmente autorizado, orgulhosamente bem informado pelas normas de gênero [...]" (JUNQUEIRA, 2012, p. 73) num lampejo de defensoria das "boas" condutas impostas pelo heterossexismo. As escolas parecem não dispor de mecanismos que amparem as queixas e denúncias dos/as alunos/as, “[...] imperando a 'lei do armário’: homossexuais são pensados como aceitos desde que não demonstrem a homossexualidade [...]" (ABRAMOVAY, 2009, p. 204).

Atitudes contrárias a essas são comuns no âmbito escolar, mas quando fecundas, tendem a reforçar a estigmatização de alunos/as LGBTQIA ao emergir com fluidez na fala de docentes naquilo que podemos definir como "estratégia de compensação". A compensação à qual nos referimos ganha reforços e contornos nítidos que se contrapõem ao infortúnio da homossexualidade, ao afirmar primeiramente as características positivas de alunos/as antes de se referir à orientação sexual deles/as. A manutenção dessa pérfida aceitabilidade exige deles/as um padrão de desempenho, em determinadas áreas, acima daquele exigido para pessoas "heterossexualizadas".

"Hoje a gente tem bastante e até são os alunos que se destacaram aqui na escola. Então são respeitados. São respeitados devido a isso também, então o aluno é homossexual, se declarou homossexual, mas o trabalho dele aqui na escola foi um trabalho que se destacou, então, até inclusive isso daí ele ganhou o respeito de todo mundo, dos colegas, dos professores [...]. Tanto que o Pitágoras [ex-aluno assumidamente homossexual] vem aqui e ele trabalha dança né. Eu falo: - Pitágoras, preciso de você pra fazer um ensaio. Então pra nós hoje é comum" (Maria Quitéria, diretora).

"Até ele [aluno gay] é bem querido" (Sofia, pedagoga).

"Ótimo, com excelentes notas. Assim, uma educação excelente [...]. E ele [homossexual] é extremamente inteligente" (Clarice, professora).

"Eu tinha dois alunos homossexuais na minha sala [uma lésbica e um gay], os dois melhores alunos" (Carmem, professora).

"Inclusive os dois [uma lésbica e uma travesti] são excelentes alunos em notas, em comportamento e tudo mais" (Brigitte, diretora).

"Inclusive nós temos uma assim [aluna lésbica] que ela é muito querida" (Natália, pedagoga).

Esse regime de manutenção e controle faz parte de um cenário de 
[...] estresse, intimidação, assédio, agressões, não acolhimento e desqualificação permanentes, nos quais estudantes homossexuais ou transgêneros são frequentemente levados/as a incorporar a necessidade de apresentarem um desempenho escolar irrepreensível, acima da média. Estudantes podem ser impelidos/as a apresentarem "algo a mais" para, quem sabe, serem tratados/as como "iguais". Sem obrigatoriamente perceber a internalização das exigências da pedagogia do armário, podem ser instados a assumirem posturas [...] dedicar-se a satisfazer e a estar sempre à altura das expectativas dos demais, chegando até a se mostrar dispostos/as a imitar condutas ou atitudes atribuídas a heterossexuais. Trata-se, em suma, de esforços para angariar um salvo-conduto que possibilite uma inclusão consentida em um ambiente hostil, uma frágil acolhida, geralmente traduzida em algo como: "É gay, mas é gente fina", que pode, sem dificuldade e a qualquer momento, se reverter em "É gente fina, mas é gay". E o intruso é arremetido ao limbo (JUNQUEIRA, 2012, p. 74).

Complementando os exemplos de Junqueira (2009a, 200b), encontramos durante nossas entrevistas com profissionais do magistério discursos semelhantes "é gay, mas é um ótimo aluno" ou "é gay, mas é tão educado" de forma a invisibilizar ou minimizar os efeitos da homossexualidade ou "é um ótimo aluno, mas é gay" ou "é tão educado, mas é gay" como se o sustentáculo da não heterossexualidade suprimisse qualquer outro atributo do sujeito. $\mathrm{O}$ determinismo desses predicados também pode estar atrelado à orientação sexual "é gay porque é um excelente dançarino" que seria muito próximo do mesmo que dizer "é um excelente dançarino porque é gay".

É importante frisar que pessoas sensíveis e amigas existem em todas as orientações sexuais e identidades de gênero. Assim como antipáticas também. Não há nada na eleição sexual de uma pessoa que a torne “[...] necessariamente mais ou menos amiga ou sensível, essa ideia parece funcionar quase como uma compensação de que para ser aceito como homossexual o sujeito precise de qualidades extras que 'compensem' o 'pequeno defeito' [...]" de ser uma pessoa LGBTQIA (BORTOLINI, 2008, s/p.).

Contraditoriamente a toda recusa e assédio dispensado aos/às alunos/as LGBTQIA, algumas profissionais do magistério defendem o "assumir-se" incentivando o "sair do armário", pois acreditam ser um meio de minimizar os efeitos ulteriores de estratégias equivocadas e também por entenderem essa transição como uma emancipação política, pois

[...] à medida que a homossexualidade se torna mais visível na sociedade enquanto uma variação legítima da sexualidade humana, haveria uma maior facilidade para [...] a "normalização" e "rotinização" de uma identidade 
homossexual; isto é, uma maior aceitação subjetiva e integração social da mesma, ainda que incompleta (SAGGESE, 2008, p. 06).

Não é possível afirmar que os riscos de discriminação seriam proporcionalmente reduzidos com o revelar-se e nem é permitido pensar em uma relação de causa/efeito. $\mathrm{O}$ argumento aqui empregado

[...] é que uma menor marginalização da homossexualidade poderia, em alguns casos, proporcionar uma maior integração desta característica à esfera pública, tornando o "armário" uma preocupação menor e fazendo, assim, com que algumas pessoas sintam-se mais seguras - o que por si só talvez não pudesse reduzir o risco de discriminação, mas modificar positivamente a percepção desse risco (SAGGESE, 2008, p. 06).

Não é incomum encontrar educadores/as "defensores/as" de uma suposta igualdade, entrarem em contradição em seus discursos ao referirem-se a discentes LGBTQIA, afirmando o quão agradável é o convívio com essas pessoas, pois são excelentes amigos/as, companheiros/as, ótimos alunos/as, ao mesmo tempo em que desconhecem, minimizam, ignoram e/ou potencializam a violência a que esses/as são submetidos/as no ambiente escolar, a começar pela própria alocução, em que negociam e incentivam o admitir-se homossexual, como forma de legitimar as demandas por direitos, o reconhecimento público e a prevenção de abordagens unívocas.

"Quando ele também [aluno homossexual] assume pra gente, fica fácil também de você trabalhar. [...] Porque daí, quando surge alguma conversa, [...] eu sei da maneira como eu vou intervir, eu sei como falar, como conversar. Por que daí ele também diz pra mim qual é a preferência dele, daí a gente pode dar uma orientação melhor. Então aquele que diz pra gente qual realmente é a opção dele pra pedagoga fica fácil você trabalhar, agora aquele que não fala fica difícil, você não sabe aonde você vai... que você tá falando de mais você tá julgando a pessoa e pode cometer um ato errado, quer dizer "pô eu tô falando alguma coisa aqui que, que não passa isso pela cabeça dele" (Cassandra, pedagoga).

"Pelo fato dele [aluno/a LGBTQIA] não poder se soltar e a gente não saber como agir também" (Cecília, diretora).

"Então foi preciso vir alunos [gays] que se colocassem. Então eu tive alunos aqui que eles se assumiram e se fizeram respeitar tanto por professores, funcionários e os próprios colegas. Então eles se assumiram, primeiramente, foi isso que aconteceu, então depois que eles assumiram o que eram realmente o pessoal passou a aceitar né [...]. Mas eles que ganharam espaço viu. Não foi a escola por si própria que foi lá e disse que eles têm direito a esse espaço. 
Não, os próprios alunos que foram conseguindo conquistar isso ẩ. (Maria Quitéria, diretora).

Nesse sentido, o dizer "eu sou gay", "eu sou lésbica" ou "eu sou bissexual”, bem como explicitar sua identidade de gênero "significa fazer uma declaração sobre pertencimento, significa assumir uma posição específica em relação aos códigos sociais dominantes" e a partir dela libertar-se do "armário" (WEEKS, 2010, p. 70), no entanto, mesmo diante do discurso dessas educadoras, de que os/as alunos/as devam assumir sua orientação sexual como uma forma de facilitar o trato da equipe diretiva e pedagógica com a temática, diante de um arsenal de informações coletadas em nossa pesquisa, podemos afirmar categoricamente que não houve indícios de que a temática em questão tenha sido discutida em sala de aula ou fora dela.

\section{CONCLUSÃO}

Em atendimento ao objetivo proposto para nosso estudo que consistiu em analisar as distintas maneiras com que a violência contra alunos/as LGBTQIA são evidenciadas na escola, foi possível percebermos que as causas da LGBTQIAfobia são reforçadas na/pela escola, influenciadas diretamente pela segregação ou indiretamente pela omissão do debate sobre a diversidade sexual e das variadas formas de assédio, impostas a alunos/as LGBTQIA.

É possível apontarmos preliminarmente que parte desse sistema de opressão pode ser resultante da inexistência de recursos, materiais didáticos, capacitação, integração entre equipe diretiva e comunidade escolar, formação inicial e continuada, dentre outras que abordem tais questionamentos, produzem efeitos diretos no exercício do magistério e na (re)produção do discurso de educadores/as, ao permitir que estes/as criem facilmente normas e padrões heteronormativos enraizados no tradicionalismo, aos quais cada aluno/a LGBTQIA deve se encaixar mantendo a invisibilidade da diversidade sexual, ou ao percebê-los/as e vê-los/as com neutralidade, caracterizando-os/as como anormais, desviantes, portadores/as de alguma patologia resultante de alguma alteração genética e/ou hormonal.

Observamos nos dicursos analisados que a permanência e a tolerância de alunos/as LGBTQIA são relativas à forma como estes/as se comportam e agem, e, de acordo com educadores/as, poderão ser alvo de insultos, caso não se adequem a padrões de normalidade. Insultos esses que são imperceptíveis tanto para a equipe diretiva quanto docente, por serem 
cultivados em tom de piadas e gozações, vistas como inofensivas, conhecidas como a pedagogia do insulto.

Diante dessas constatações consideramos que a escola desempenha um papel primordial no processo de formação do ser social, possibilitando o exercício de uma cidadania plena. Como prerrogativa, se faz necessária a inserção de temas que possuem grande impacto e relevância na vida social, que insistentemente desafiam princípios democráticos e éticos por meio da regulação e manutenção de injustificáveis e distintos prejuízos sociais como a diversidade sexual e o combate e prevenção à violência destinada a pessoas LGBTQIA.

Portanto, discussões sobre a existência e permanência desses/as alunos/as; a subversão de estratégias normalizadoras; a valorização das diferenças e promoção da cultura do respeito devem ganhar espaço formal no processo de escolarização por meio dos livros, dos conteúdos didáticos, na prática pedagógica; discutidas em eventos que versem sobre a diversidade sexual escolar; inclusão de conteúdos sobre gênero e diversidade sexual no projeto escolar com vistas à extinção da cultura heteronormativa; debate entre escola e demais esferas sociais como saúde e assistência social sobre ações e propostas de enfrentamento à LGBTQIAfobia; estabelecimento de políticas assistenciais e de saúde para alunos/as LGBTQIA em situação de vulnerabilidade; oferta de atendimento psicossocial a alunos/as expostos às distintas violências por orientação sexual e identidade de gênero que escape ao determinismo biológico, para que possam superar traumas e dar continuidade ao processo de escolarização; implementação de estratégias por parte da escola, das Secretarias Municipais e Núcleos Regionais de Educação, que permitam esses/as alunos/as denunciarem situações em que sintam seus direitos violados; exercício do diálogo entre equipe diretiva, docência e comunidade escolar; que diretores/as, pedagogos/as e professores/as coloquem seus sentidos a postos e vejam as distintas maneiras de posicionar a sexualidade como algo positivo, ouçam com atenção os anseios dessa minoria e executem o poder do discurso defendendo o respeito a todos/as indistintamente.

À guisa de conclusão convidamos nossos/as leitores/as a refletirem que vivemos um momento no qual todos somos agentes responsáveis por uma educação igualitária, que não comporta discursos docentes sobre a ausência do debate da diversidade sexual e homofobia. $\mathrm{O}$ maior desafio que se apresenta na atualidade para nós enquanto educadores/as é o de abrir-se para esse debate. Portanto, os zarus acerca da diversidade sexual e a promoção da cultura do respeito devem ser afastados do interior da escola e as discussões acerca da temática não devem 
ser pautada unicamente pela presença de alunos/as LGBTQIA no cotidiano escolar, mas porque tal conduta infere na realidade social marcando, regulando e normatizando pessoas por meio de uma conduta moral hegemônica heteronormativa, que insistentemente se desdobra na violação de direitos e ocasiona os mais distintos prejuízos sociais, ao retirar do ato de viver o livre exercício dos distintos modos de ser e sentir-se humano. O prejuízo é geral, mas uns serão sempre chamados a pagar um preço maior que outros.

\section{REFERÊNCIAS}

ABRAMOVAY, Miriam (Coord.). Revelando tramas, descobrindo segredos: violência e convivência nas escolas. Brasília: Rede de Informação Tecnológica Latino-Americana RITLA, Secretaria de Estado de Educação do Distrito Federal - SEEDF, 2009. Disponível em: <http://www.saude.sp.gov.br/resources/crt/central-de-arquivos/prevencao/bibliografia-deapoio/revelando_tramas_descobrindo_segredos_violencia_e_convivencia_nas_escolas..pdf $>$. Acesso em: 04 jun. 2017.

BARROS, Suzana da Conceição de. RIBEIRO, Paula Regina Costa. QUADRADO, Raquel Pereira. Sexualidade: olhares das equipes pedagógicas e diretivas. Currículo sem Fronteiras, v. 11, n. 2, Jul/Dez 2011. p. 179-203.

BENTO, Berenice. Na escola se aprende que a diferença faz a diferença. Estudos Feministas, Florianópolis, mai./ago. 2011, p. 549-559.

BONI, Valdete; QUARESMA, Sílvia Jurema. Aprendendo a entrevistar: como fazer entrevistas em Ciências Sociais. Revista Eletrônica dos Pós-Graduandos em Sociologia Política da UFSC, Florianópolis, v. 2, n. 01, jan-jul. 2005, p. 68-80.

BORGES, Zulmira Newlands; PASSAMANI, Guilherme Rodrigues; OHLWEILER, Mariane Inês; BULSING, Muriel. Percepção de professoras de Ensino Médio e fundamental sobre a homofobia na escola em Santa Maria (Rio Grande do Sul/Brasil). Educar em Revista. Curitiba: UFPR, n. 39, jan./abr. 2011, p. 21-38.

BORRILO, Daniel. A homofobia. In: LIONÇO, Tatiana; DINIZ, Débora (Org.). Homofobia \& Educação: um desafio ao silêncio. Brasília: Letras Livres: EdUnB, 2009, p. 15-46.

BORTOLINI, Alexandre. Diversidade sexual na escola. Rio de Janeiro: Pró-Reitoria de Extensão/UFRJ, 2008.

BRASIL. Ministério da Saúde, Secretaria de Vigilância em Saúde. Departamento de DST, AIDS e Hepatites Virais. Adolescentes e jovens para uma educação entre pares: diversidades sexuais. Brasília: Ministério da Saúde, v. 8, 2011. 
BUTLER, Judith. Corpos que pesam: sobre os limites discursivos do "sexo". In: LOURO, Guacira Lopes (Org.). O corpo educado. Tradução: Tomaz Tadeu da Silva. 3. ed. Belo Horizonte: Autêntica, 2010, p. 151-172.

CAETANO, Márcio Rodrigo Vale. Rompendo fronteiras e problematizando as diferenças sexuais. In: RIBEIRO, Paula Regina Costa. SILVA, Fabiana Ferreira da. MAGALHÃ̂SS, Joanalira Corpes. QUADRADO, Raquel Pereira (Orgs.). Educação e Sexualidade: identidades, famílias, diversidade sexual, prazeres, desejos, preconceitos, homofobia...Rio Grande: Editora da FURG, 2008, p. 158-171.

CARVALHO, Maria Eulina Pessoa de. Relações entre a família e escola e suas implicações de gênero. Cadernos de Pesquisa, n. 110, jul. 2000, p. 143-155.

. Modos de educação, gênero e relações escola-família. Cadernos de Pesquisa, v. 34, n. 121, jan./abr. 2004, p. 41-58.

DINIS, Nilson Fernandes. Homofobia e educação: quando a omissão também é signo de violência. Educar em Revista, n. 39, jan./abr. Curitiba: Editora UFPR, 2011, p. 39-50.

DOVIDIO, John F. GLICK, Peter. RUDMAN, Laurie A. Introduction: Reflecting on The Nature of Prejudice: Fifty Years after Allport. In: DOVIDIO, John F.; GLICK, Peter; RUDMAN, Laurie A. On the Nature of Prejudice: Fifty Years after Allport. Blackwell Publishing: USA, 2005, p. 1-16.

FERRARI, Anderson. O quê se fala e o quê se cala sobre o homoerotismo masculino: discursos, práticas e posturas dos professores diante do fato e do assunto. Anped, GT Sociologia da Educação, 2000. Disponível em <http://www.anped.org.br/reunioes/23/textos/1412t.PDF>. Acesso em: 17 jan. 2017.

FONTES, Malu. Ilustrações do silêncio e da negação. In: LIONÇO, Tatiana. DINIZ, Debora (Org.). Homofobia \& Educação: um desafio ao silêncio. Brasília: Letras Livres: EdUnB, 2009, p. $99-114$.

FOUCAULT, Michel. Entrevista a James O’Higgins (1982). In: BARRETO, Jorge Lima. Um diálogo sobre os prazeres do sexo. Nietzsche, Freud e Marx. Theatrum Philosoficum. Tradução de Maria Cristina Guimarães Cupertino. São Paulo: Landy, 2000, p. 11-45.

Vigiar e punir: nascimento da prisão. Tradução de Raquel Ramalhete. 29 ed. Petrópolis/RJ: Vozes, 2004.

FOUCAULT, Michel. A ordem do discurso. 15. ed. São Paulo: Loyola, 2007.

FURLANI, Jimena. Mitos e tabus da sexualidade humana: subsídios ao trabalho em educação sexual. 3. ed. Belo Horizonte: Autêntica, 2007. 
GREEN, Bill. BIGUM, Chris. Alienígenas na sala de aula. In: SILVA, Tomaz Tadeu da (Org). Alienígenas na sala de aula: uma introdução aos estudos culturais em educação. 5. ed. Petrópolis, RJ: Vozes, 1995, p. 208-243.

HALL, Stuart. A Identidade Cultural na Pós Modernidade. Tradução: Tomaz Tadeu da Silva; Guacira Lopes Louro. 11. ed. Rio de Janeiro, RJ: DP\&A, 2006.

Quem precisa da identidade? In: SILVA, Tomaz Tadeu da (Org.). Identidade e Diferença: a Perspectiva dos Estudos Culturais. 7. ed. Petrópolis, RJ: Vozes, 2007, p. $103-$ 133.

JUNQUEIRA, Rogério Diniz. Homofobia nas escolas: um problema de todos. In:

(Org.). Diversidade Sexual na Educação: problematizações sobre a homofobia nas escolas. Ministério da Educação: SECADI/MEC. Brasília, 2009a, p. 13-52.

"Aqui não temos gays nem lésbicas": estratégias discursivas de agentes públicos ante medidas de promoção do reconhecimento da diversidade sexual nas escolas. Bagoas. n. 04, p.171-190, 2009b.

A Pedagogia do Armário: heterossexismo e vigilância de gênero no cotidiano escolar. Revista Educação On-line PUC, Rio de Janeiro, n. 10, p. 64-83, 2012.

LIBERATUS conscientiae. Os três macacos sábios. 2010. Disponível em <http://liberatusconscientiae.blogspot.com.br/2010/03/os-tres-macacos-sabios.html>. Acesso em: 20 mar. 2013.

LOURO, Guacira Lopes. Gênero, sexualidade e educação. Uma perspectiva pósestruturalista. Petrópolis/RJ: Vozes, 1997.

Heteronormatividade e Homofobia. In: JUNQUEIRA, Rogério Diniz (Org.). Diversidade Sexual na Educação: problematizações sobre a homofobia nas escolas. Ministério da Educação: SECADI/MEC. Brasília, 2009, p. 85-95.

. Pedagogias da sexualidade. In: LOURO, Guacira Lopes (Org.). SILVA, Tomaz Tadeu da (Trad.). O corpo educado. 3. ed. Belo Horizonte: Autêntica, 2010, p. 07-35.

MORAES, Roque. Análise de conteúdo. Revista Educação, Porto Alegre, v. 22, n. 37, 1999, p. 7-32.

OLIVEIRA JÚNIOR, Isaias Batista de. O/A diretora não viu, a pedagoga não ouviu e a professora não quer falar: discursos docentes sobre diversidade sexual, homofobia e "Kit Gay". 260 f. (Dissertação de Mestrado). Programa de Pós Graduação em Educação, Universidade Estadual de Maringá, Paraná, 2013.

Professores e famílias não convencionais: uma proposta de intervenção e formação pelas lentes do cinema. (Tese de Doutorado). Presidente Prudente: 2016, 257f. 
PARANÁ. Gênero, orientação Sexual e Relações Étnico-Raciais. Rio de Janeiro: CEPESC; Brasília: SPM, 2009.

PASSOS, Maria Cônsuelo. Homoparentalidade: uma entre outras formas de ser família. Psi. Clin. Rio de Janeiro, vol. 17, n. 2, 2005, p. 31-40.

PERES, Willian Siqueira. Cenas de exclusões anunciadas: travestis, transexuais, transgêneros e a escola brasileira. In: JUNQUEIRA, Rogério Diniz (Org.). Diversidade Sexual na Educação: problematizações sobre a homofobia nas escolas. Ministério da Educação: SECADI/MEC. Brasília, 2009, p. 235-263.

SAGGESE, Gustavo Santa Roza. Quando o armário é aberto: visibilidade, percepções de risco e construção de identidades no coming out de homens homossexuais. Fazendo Gênero 8 - Corpo, violência e poder. Florianópolis, 2008.

SALVA, Sueli; STIMAMIGLIO, Neusa Maria Roveda. Ser menino e ser menina também se aprende na escola. In: Seminário Corpo, gênero e sexualidade: instâncias e práticas de produção nas políticas da própria vida. Anais... Rio Grande, 2011, p. 1361-1370.

SANTOS, Manoel Antônio dos. BROCHADO JÚNIOR, José Urbano. MOSCHETA, Murilo dos Santos. Grupo de pais de jovens homossexuais. Revista Eletrônica de Saúde Mental Álcool e Drogas. Vol. 03, n. 02, São Paulo, 2007, p. 1-16.

SEFFNER, Fernando. Equívocos e armadilhas na articulação entre diversidade sexual e políticas de inclusão escolar. In: JUNQUEIRA, Rogério Diniz (Org.). Diversidade Sexual na Educação: problematizações sobre a homofobia nas escolas. Ministério da Educação: SECADI/MEC. Brasília, 2009, p. 127-139.

SILVA, Tomaz Tadeu da. A produção social da identidade e da diferença. In: (Org.). Identidade e Diferença: a Perspectiva dos Estudos Culturais. 7. ed. Petrópolis/RJ: Vozes, 2007, p. 73-102.

SIMIONATO Marlene Aparecida Wischral. OLIVEIRA, Raquel Gusmão Funções Transformações da Família ao Longo da História. Anais...I Encontro Paranaense de Psicopedagogia - ABPpPr. nov./2003, p. 57-66.

SOUSA FILHO, Alípio de. A resposta gay. 2013. Disponível em <http://www.cchla.ufrn.br/alipiosousa/index arquivos/ARTIGOS\%20ACADEMICOS/ARTIGOS PDF/A \%20RESPOSTA\%20GAY.pdf>. Acesso em: 13 jun. 2017.

SWAIN, Tania Navarro. Os limites do corpo sexuado: diversidade e representação social. In: PARANÁ. Secretaria de Estado da Educação. Superintendência de Educação. Departamento de Diversidade. Núcleo de Gênero e Diversidade. Sexualidade. Curitiba: SEED. 2009, p. 121-129.

WEEKS, Jeffrey. O corpo e a sexualidade. In: LOURO, Guacira Lopes (org.). O corpo educado: pedagogias da sexualidade. 3. ed. Belo Horizonte: Autêntica, 2010, p. 35-82. 


\section{Notas}

${ }^{i}$ Termo empregado como forma de sintetizar as expressões cotidianas de hostilidade, às quais os indivíduos LGBTQIA são submetidos.

ii A heteronormatividade se desenvolve cotidianamente nas práticas de reiteração compulsória a serviço da consolidação do imperativo heterossexual em detrimento das outras formas de orientação sexual e materialização de normas regulatórias, que, em partes, são aquelas da hegemonia sexual, por meio de uma relação binária, na qual uma das formas de manifestação da sexualidade recebe um valor positivo e privilegiado - a heterossexualidade, enquanto a outra recebe um cunho negativo - a homossexualidade. 